\title{
Information System Challenge on Performance Measurement Data in Indonesian Public Hospitals
}

\author{
Wulan I R Sari \\ Faculty of Economics and Business, Mulawarman University, Indonesia \\ wulan.sariefeb.unmul.ac.id
}

\begin{abstract}
According to Ministry of Internal Affairs Regulation [1], there are two sets of performance measurements data which apply to public hospitals as Local General Services Bodies (Badan Layanan Umum Daerah/BLUD): financial data and nonfinancial data on performance measurements. As public hospitals, public hospitals are owned by different levels of government that provide different levels of funding for the services offered by each hospital. There are differences in the scope of services due to the class of each hospital and each hospital's strategic management. However, each public hospital has the ability and creativity to maintain quality in services and activities based on their own strategic management and governance as a Local General Services Body. The aim of this study is to understand the cycle of data collecting and reporting processes on performance measurement data in public hospitals. A qualitative approach and a multiple case study design are used to enable the exploration of the data gathering practices and processes on performance measurement data of the four public hospitals.

Results show the four public hospitals use financial data (such as revenue growth, cost trends and financial statements), and non-financial data (such as administrative and clinical performance), to measure their performance. The four public hospitals in this study face similar difficulties in the collecting of financial data, such as in relation to the preparation of financial statements. On the other hand, each of the four public hospitals has well-developed abilities to processes non-financial data, such as coverage of health services, epidemic infectious diseases and the maternal mortality rate, in decision-making processes.
\end{abstract}

Keywords - information, system, performance, measurement, data, hospitals.

\section{INTRODUCTION}

There is a new management approach for public hospitals in Indonesia if public hospitals choose to be a local general service body (BLUD). One of the aspects of this new approach is flexibility in financial management. According to Ministry of Internal Affairs Regulation [1], this new mechanism on financial management allows public hospitals to use revenues from services to pay for expenses that impact on services, including the direct and indirect costs of services. As a consequence of this new mechanism, public hospitals will be required to provide a range of documents, including strategic business planning, governance, standard minimal of services, and financial statements that include fiveyear predictions. This new approach to financial management influences public hospitals in many ways, such as enabling innovation in new services and greater awareness of achievements of hospital targets.

However, Ministry of Internal Affairs Regulation [1] requires public hospitals to report both financial and non-financial performance, such as minimal standards of services (SPM) for hospitals [2] and for health sector development [3]-[4]. Financial reporting is easier to do than non-financial reporting because public hospitals must report to local government in order to get routine funding (budget). By comparison, non-financial performance, such as reporting on minimum standards of service, is significantly harder to do because it has little impact on the overall operation of the hospital, even though it is required by other institutions. There are two minimum standards of services (SPM): one for hospitals, and another for health development. Although the name (SPM) is the same, they have different purposes and different objectives.

Moreover, public hospitals in Indonesia have an obligation to report annually on their financial and non-financial performance, in relation to efficiency, effectiveness and equity of services. Therefore, the performance of public hospitals is increasingly used for decision-making in organizations and for reporting information to relevant administrative and political bodies [5]. Performance measurements data meet requirements from both internal and external stakeholders, such as non financial performance.

Non-financial performance in the public hospital is divided into administrative [6]-[8] and clinical 
performance [9]-[10]. Administrative performance is concerned with the continuous assessment of patient satisfaction with health services in the public hospital, while clinical performance measures outcomes of clinical processes by reviewing medical records as evidence of actual medical practice.

An example is this is patient complaints and satisfaction being used as ways to measure administrative and clinical performance [6]-[10]. Administrative performance relates to program and service quality [8]. Given the role of hospitals in providing services to patients, clinical performance is more important than administrative performance. Indirectly, clinical performance becomes one of the methods to assess both public hospital quality management of services and physicians. That is, clinical performance is a signal to the physicians and managers in the hospital of the quality of services. It is important because such data will indicate if there is something wrong with managerial services or clinical services. Thus, reliable data is crucial to trace and to solve the problems and to improve health provision in the public hospitals.

Even though public hospitals are owned by different levels of government that provide different levels of funding for the services offered by each hospital. There are differences in the scope of services due to the class of each hospital and each hospital's strategic management. However, each public hospital has the ability and creativity to maintain quality in services and activities based on their own strategic management and governance as a Local General Services Body. As previos studies show inconsistent results between regulatory processes and quality outcomes [11] and lack on pratices and processes of quality improvement due to limited human resources and lack of competent staff [12]. Thus, the aim of this study is to understand the cycle of data collecting and reporting processes on performance measurement data in public hospitals.there are such policies supporting for quality improvement.

\section{METHODS}

A qualitative approach and a multiple case study design are used to explore how public hospitals collect and report performance measurement data. Through qualitative research methods, "whereby the researcher aims to understand and interpret experiences by viewing the world through the eyes of the individuals being studied" [13]. Also, qualitative research adopts a "naturalistic approach" conducting the study in workplaces where the action takes place rather than in laboratories, and by naturalistic conversations (interviews) rather than by constrained response surveys [14]. This methods enabled the exploration of the cycle of data collecting and reporting processes on performance measurement data in public hospitals.

This study uses a multiple case study approach comparing the four public hospitals. This is an extension of a single case study design [15]. These four case studies explore how public hospitals collect and report performance measurement data. Cases are selected on the basis that they reflected the same class of public hospitals from different provinces and different classes from the same province (Table 1). This strategy was chosen because the researcher was concerned with each public hospital's individual circumstances. This approach uses interviews, direct observation, and documentary analysis in the four public hospitals and adopts a thematic approach for data analysis.

TABLE 1

THE CLASSES and LOCATIONS of the FOUR CASE STUDIES

\begin{tabular}{|l|c|c|}
\hline Llass of hospitar & Province 1 & Province 2 \\
\hline B Class hospital & Hospital P & Hospital A \\
\hline C Class hospital & Hospital W & Hospital S \\
\hline
\end{tabular}

The individuals selected for interviews were people who have, or have had, direct experience with the Indonesian public hospital system. The basis of this sample selection is consequently purposive sampling [16]. Moreover, those sampled are relevant to the research questions [15]. There is a group of respondents in this study, the four public hospitals. There were 16 staff. 
TABLE II

THE TYPE of INFORMATION BEING SOUGHT for EACH GROUP'S OBJECTIVES

\begin{tabular}{|c|l|l|}
\hline Group & \multicolumn{1}{|c|}{ Objectives } & \multicolumn{1}{c|}{ Questions } \\
\hline 1 & $\begin{array}{l}\text { To understand the } \\
\text { cycle of data } \\
\text { collecting and } \\
\text { reporting } \\
\text { processes on } \\
\text { performance } \\
\text { measurement data. }\end{array}$ & $\begin{array}{l}\text { 1. How do you record and collect data for the } \\
\text { performance measurement report? } \\
\text { 2. To what extent is the performance } \\
\text { measurement report beneficial for quality } \\
\text { services improvement? }\end{array}$ \\
& $\begin{array}{c}\text { 3. Do management evaluate the performance } \\
\text { measurement report? } \\
\text { 4. How does data management impact health } \\
\text { services in this hospital? } \\
\end{array}$ & $\begin{array}{c}\text { Shat data is needed to improve the quality } \\
\text { of services? }\end{array}$ \\
\hline
\end{tabular}

\section{RESULTS}

Performance measurement data are needed to ensure both clinical performance and administrative performance existing at each public hospital. Besides being required by regulations, performance reporting is also used to develop service planning as part of the process of improving the service quality of public hospitals. Public hospitals can develop a new service in order to either provide better access to patients or to meet the hospital's needs.

In addition, quality improvement in the public hospitals is influenced by the process of data gathering. In the process of data collecting, there are many activities that are involved with improvement of services, administration of documents, and coordination with other institutions. Thus, the public hospitals need to ensure that data collecting and processing of information is valid and reliable for monitoring and improving services and external reporting to government agencies at national, provincial or local levels.

To describe the data collection in each public hospital, this section will show the cycle of data collection, the process for gathering and the use of data in the four public hospitals. Even though each hospital is from a different class of hospital, each follows a similar cycle of data collection. This is because the data collection cycle is a response to government regulation, which specifies daily, weekly, monthly or annual reporting. However, there are differences at each public hospital. I found from the fieldwork that there were differences in the process and the use of data due to staff competence to collect data, public hospital dynamics, and the involvement of external institutions and each hospital's programs on services improvement. Also, the type of data sought has an influence on the public hospital's abilities to collect and to use the data. For example, Hospital P focuses on maternal mortality rate because this rate is a focus for international, national and local institutions seeking improvements in health services and development. Thus, this data on maternal health at Hospital P is supposed to be readily available and up-to-date. This illustrates that there are differences in the process and the use of data at each public hospital because such use of data depends on the specific circumstances in each public hospital.

\section{A. The Cycle of Data Collection}

The data collection cycle in the four public hospitals follows government regulations. There are different cycles for data that are set out in the regulations for public hospitals, such as daily, weekly, monthly, quarterly [2]-[3] and annual bases for documentation and reporting [17]-[18]. These depend on the purpose of the hospital and its relationship to external institutions. For example, data on diseases and the standard minimum of services for health development are asked for by the national Ministry of Health and the provincial or regency health departments on a monthly basis. The focus for these reports is on the kinds and quality of service being delivered. On the other hand, the local governments seek to monitor the budgets at the public hospitals by requiring financial reports each quarter. This interim reporting of budgets helps a public hospital to monitor both money and activities.

Fig. 1 shows the cycle of data collecting and reporting processes for the different management areas within the hospitals and the external institutions. Daily data on financial and nonfinancial performance is collected and is compiled by registration units, wards, cashiers and treasurers in each hospital. Then, at the end of the day, some data are reported to the data manager, such as the number of out-patients and expenses on hospital supplies, and some data need further processing due to adjustment processes with other divisions and institutions, such as adjustments on revenue from insurance out-patients that it needs to report to the financial division for recording and imbursement 
process. Accumulation of daily data to weekly becomes monthly data.

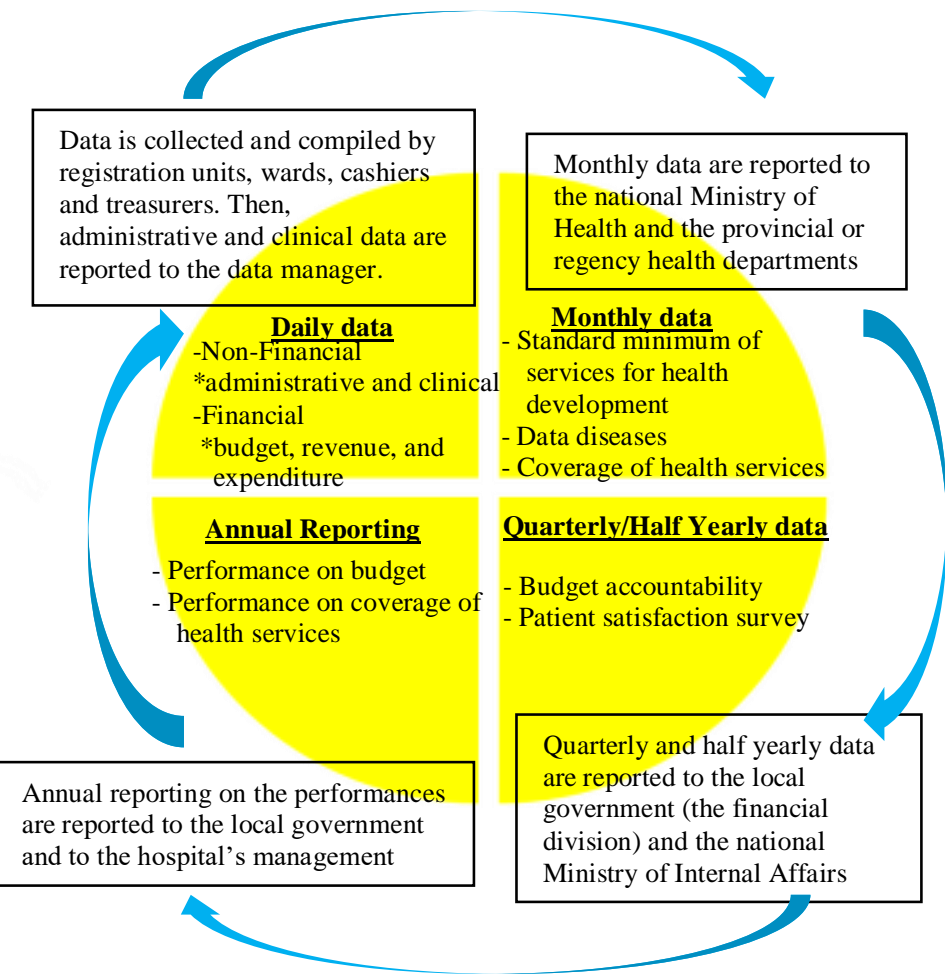

Sources: Based on fieldwork, [3], [17]-[18].

Fig.1 The cycle of data collecting and reporting at the four public hospitals

Further, monthly data on the standard minimum of services for health development, data diseases, and coverage of health services are reported to the national Ministry of Health and the provincial or regency health departments. This process takes place each month until quarter and semester data are reported to the local government (for budget accountability) and to the national Ministry of Internal Affairs on patient satisfaction (as an assessment of administrative performance).

At the end of the year, there is annual reporting on the performance of the hospital against its budget to the local government and performance on coverage of health services to the hospital's management. These annual reporting results will be used in the database to compare performance in the next year's activities.

The government regulations from national, provincial and local levels help public hospitals to both collect and use data on performance. For example, one senior professional and manager explained:

...We commonly need pressure from regulation

to improve. If there is not regulation, we will do what we want because [without regulation] we can run the hospital and get more money...However, through accreditation, we learn to do processes better gradually (G1_W3).

Such pressure eventually eases, encouraging public hospitals to gradually change the way they collect data, which also helps staff to learn how to use and collect data in everyday practice. For example, public hospitals are starting to commit on data awareness, gradually improving hospital management by following regulations and learning to govern from others, such as other public hospitals and hospital management consultants. Also, all levels of management are starting to be involved with these changing processes. Top management (the director and vice-directors), are involved with this commitment, while middle and lower management are trying to change routines on data recording and to evaluate services by using these data as a new staff learning process. At the same time, staff are also using data to improve services. Thus, these activities help inspire management to encourage staff to write what they do and do what they write for each of their activities in order to maintain up-to-date data. This is a great help to public hospitals in accreditation processes.

\section{B. Financial Data}

Preparing and publicly reporting financial data, such as financial statements, is required of public hospitals as Local General Services Bodies (Badan Layanan Umum Daerah/BLUD). A financial statement consists of a balance sheet, profit and loss (revenues and expenses) reporting, cash flow, and footnotes to the financial statements [19]. Under the reporting requirements, financial statements are included in the strategic business plan prepared by each hospital. Thus, financial statements are used to measure annual financial performance. For example, revenue growth will be measured by comparing current revenue and previous revenue. 
The four hospitals have difficulties collecting and using data in financial statements. This is because there are barriers with data processing. For example, financial staff lack technical skills (expertise) and the Ministry of Internal Affairs and the Ministry of Finance regularly and frequently change financial reporting requirements, such as codes in the chart of accounts and processes of recognition on services (business transactions). The financial divisions in each of the four public hospitals record, report, and keep financial data everyday, demonstrating good bookkeeping practices by the cashiers and the cash-in treasurers. However, these staff members cannot transform the financial data collected into financial statements because of their lack expertise, time limits, and poor coordination with other institutions.

\section{Non Financial Data: Performance Reporting}

Performance reporting on the budget and performance on coverage of health services are required by government regulation. Therefore, the four public hospitals collect and regularly report data to the Ministry of Health, the Health Department and the financial division of local government. Such reports are provided on a monthly and quarterly basis. There are also specific forms to report to those institutions. Thus, the amount of time it takes to collect data for this type of reporting is not a significant problem.

On the other hand, there are differences in the use of this reporting in the decision- making process. Three of the public hospitals are not interested in the data for this reporting as they think that this reporting is more concerned with complying with government regulations than with responding to hospital needs to improve the quality of services. In contrast, the fourth hospital sees this reporting as a way to improve both services and facilities. For example, Hospital $\mathrm{P}$ uses clinical data on maternal mortality rates to improve medical staff expertise and to ensure that there are sufficient facilities to provide proper services to the patients. This encouraged Hospital $\mathrm{P}$ to propose a budget for advanced education for physicians and for sufficient facilities to improve patient access to better health provisions.
There are reasons behind the use of performance reporting on the budget and coverage of service. For example, Hospital A is concerned with budget use because staff who are responsible for budget monitoring understand the process of budget administration and clinical services. Thus, they are aware of how the hospital can improve and provide better services to the patients by improving access to equipment and facilities for services. In addition, Hospital P focuses on coverage of health services, such as the maternal mortality rate. This is because the maternal mortality rate is a crucial indicator for health development and the quality of health provision at a public hospital. The maternal mortality rate is monitored by local, national and international institutions, such as the health department, the Ministry of Health, and the World Health Organization [2], [20]. In addition, there is a lack of staff competence and skill, which impacts on performance data use in financial statements and performance reporting on budget and coverage of health services. For example, from direct observation in a management meeting at Hospital A, the director is always updated with information about programs and the realization of budget.

\section{IV.DISCUSSION}

There are two broad types of data that result from the public hospitals' management of services: financial and non-financial data [21]-[24]. In terms of financial data, the emphasis on the budget means that each public hospital must monitor its revenue and expenses. By monitoring the budget, the hospital can identify where its planned and actual expenditure differ.

For example, one of reasons for this deviation may be the higher expense for unexpected staff training (such training may be necessary due to the increased number of new types of diseases or illnesses). Data collected on these training expenses and the number of staff involved can help explain the difference between planned and actual expense. Even though the training expense is higher than the budget, hospital top management will encourage the training division to continue this training. This is because training for staff is necessary to improve staff skills to tackle new diseases which arise in the surrounding hospital area and could attack 
community health safety. With skilled staff, patients could get better treatment and recover properly. Moreover, once the importance of data on non-financial performance is recognized it can play a more important role than financial performance data in improving services.

\section{A. Performance Measurement Data}

Ideally, performance measurement data should support decision-making processes in each of the hospitals. However, it is a challenge for hospitals because there are existing factors that have an impact on organizational decision-making processes, such as the type of data, expertise of staff [25] and the public hospital's commitment to the priority of programs [26]. These circumstances are found in two of the four public hospitals in this study.

The variation in the use and non-use of performance data across the four hospitals is a significant finding of this research. As well, to understand the process of measuring an activity, it should be part of the normal course of organizational routines. In such circumstances, through measuring an activity, public hospitals can use measurement for control purposes and to encourage continuous improvement [27]. Thus, an organization has the opportunity to do one activity to achieve two objectives. For example, when a public hospital measures speed of services, it is also measuring staff skills and patient satisfaction.

Through a qualitative analysis, the identification and exploration of the performance measurement data use within public hospitals in Indonesia to improve quality can be revealed. This is possible because it follows that the impact of processes can influence the quality of health services as a result of the use of performance measurement data in decision-making processes.

This study also shows that performance measurement can produce significant improvements in services quality. This can happen if public hospitals are able to undertake continuous improvement as long as the data used is relevant, accurate, and sufficiently precise to enable processes to change. This means that processes of improvement are integral to the work of the public hospitals. However, there needs to be both competent staff to do the right things, and better routines and organizational learning to ensure that the processes that should be performed are performed, and that they are on the right track.

The importance of competent staff in influencing organizational routines in data gathering and use in the decision-making process. Having staff with appropriate skills and competencies is one of the key factors in ensuring that routines and learning become established in an organization [28]. Also, organizations need qualified staff to do the right things and to follow the organization's mission and strategy in order to provide excellent health services. This is because organizational learning is not a sudden process but requires the intentional use of different strategies to set it in motion. It requires consistency and learning across the organization [29].

\section{CONCLUSIONS}

Such regulations on the quality of hospital services encourage public hospitals to do better on data management. However, they are difficult to apply due to technical problems, such as lack of competent staff and no specific technical guidance. For example, in the case of accreditation process, the four hospitals understand that continuous quality improvement is important in improving health provision. Accreditation processes encourage public hospitals to become more aware of the data.

To upgrade the competency of staff, the four public hospitals use training to improve staff skills in financial, administrative and clinical performance. This method is able to help public hospitals apply internal business processes and learning growth of organizations but it is hard to improve staff skills to create financial statements. This is because the effort in the financial perspective is not optimum, and because staff transfer from other public hospitals, which makes it difficult to implement financial statement routines.

To fulfil their obligations to central and local government, public hospitals must report their performance as a part of their commitments to budget transparency and accountability. Thus, government obligations shape public hospitals' practices and hospitals' routines are influenced by government regulations. To ensure public hospitals 
improve on these areas, it needs changing in the way of staff learning from data and using data for quality improvement. Hence, future research it needs focusing on performance measurement data use in quality improvement routines of public organizational learning.

\section{ACKNOWLEDGMENT}

This research took place through the University of Canberra and I owe my greatest gratitude and sincere thanks to Dr Chris Sadleir and Dr Anni Dugdale for their support and guidance. I would also like to express my appreciation to the Ministry of Research, Technology and Higher Education for the scholarship allowing me to pursue this study.

\section{REFERENCES}

[1] Ministry of Internal Affairs Regulation. (2007). No. 61: Technical guidance of financial management for local general services body (Badan layanan umum daerah/BLUD). Jakarta.

[2] Ministry of Health. (2008). Keputusan Menteri Kesehatan No. 129/Menkes/SK/II/2008: Minimal standard services for hospital. Jakarta.

[3] Ministry of Health. (2008). Ministry of Health Regulation of Republic of Indonesia No: 741/Menkes/PER/VII/2008, Standard Minimum of Services for Health Sector at Regency/City. Jakarta.

[4] Ministry of Health. (2008). Keputusan Menteri Kesehatan No. 828/MENKES/SK/IX 2008: Technical guidance for minimal standard of services for health sector at regency/city. Jakarta.

[5] van Helden, G. J., Johnsen, A., \& Vakkuri, J. (2008). Distinctive Research Patterns on Public Sector Performance Measurement of Public Administration and Accounting Disciplines. Public Management Review, 10 (5), 641-651.

[6] Vigoda, E. G., \& Yuval, F. (2003). Managerial quality, administrative performance and trust in governance: Can we point to causality?. Australian Journal of Public Administration, 62 (3), 12-25.

[7] Vigoda, E. G., \& Yuval, F. (2003). Managerial quality, administrative performance and trust in governance revisited: A follow-up study of causality. The International Journal of Public Sector Management, 16 (7), 502-522.

[8] Kelly, J. M. (2003). Citizen satisfaction and administrative performance measures: is there really a link?. Urban Affairs Review, 38 (6), 855866.

[9] Landon, B. E., Normand, S. T., Blumenthal, D., \& Daley, J. (2003). Physician clinical performance assessment: Prospects and Barriers. American Medical Association, 290 (9), 1183-1189.

[10] Veloski, J., Boex, J. R., Grasberger, M. J., Evans, A., \& Wolfson, D. B. (2006). Systematic review of the literature on assessment feedback and physicians' clinical performance: BEME guide no.7. Medical Teacher, $28(2), 117-128$.

[11] Hearld, L. R., Alexander, J. A., Fraser, I., \& Jiang, H. J. (2008). Review: How do hospital organizational structure and process affect quality of care?: A critical review of research methods. Medical Care Research and Review, 65 (3), 259-299.

[12] Sari, W. (2016). Indonesia and the Challenge of Improving Services in Public Hospitals via Performance Measurement. Australia, University of Canberra: PhD Thesis.

[13] Walter, M. (2010). Social Research Methods. New York, Oxford University Press: 2nd edition.

[14] Denzin, N.K., \& Lincoln, Y.S. (2005). Handbook of qualitative research. California, Thousand Oaks: Sage Publication.

[15] Bryman, A. (2012). Social research methods. New York, Oxford University Press: 4th edition.
[16] Mabry, L. (2008). Case study in social research, The Sage Handbook of Social Research Methods. London, Sage Publications.

[17] Ministry of State Apparatus and Bureaucracy Reforms Decree. (2004). Keputusan Menteri Aparatur Negara No: KEP/25/M.PAN/2/2004: General guidance for index of community satisfaction at services unit of government institution. Jakarta.

[18] Indonesian Government Regulation. (2006). No 8: Financial and performance reporting for government institution. Jakarta.

[19] Financial Accounting Standards Board (FASB). (1985). Statement of financial accounting concepts (SFAC) No. 6, Elements of Financial Statements: A Replacement of FASB Concepts Statement No. 3 (incorporating an amendment of FASB Concepts Statement No. 2). Norwalk.

[20] World Health Organization. (2014) World Health Statistics 2014. Geneva.

[21] Scheiwe, D. (1995). Strategic planning and financial management in Clinton, M., \& Scheiwe, D. Management in the Australian health care industry, Melbourne, Addison Wesley Longman.

[22] Ballantine, J., Brignall, S., \& Modell, S. (1998). Performance measurement and management in public health services: a comparison of U.K and Swedish practice. Management Accounting Research, 9, 71-94.

[23] Stevanovic, V., Feek, C., \& Kay, R. (2005). Using routine data for benchmarking and performance measurement of public hospitals in New Zealand. Benchmarking: An International Journal, 12, (6), 498507.

[24] Bazzoli, G. J., Chen, H., Zhao, M., \& Lindrooth, R. (2008). Hospital financial condition and the quality of patient care. Health Economics, 17, 977-995.

[25] Garengo, P., Biazzo, S., \& Bititci, U. S. (2005). Performance measurement system in SMEs: A review for a research agenda. International Journal of Management Review, 7 (1), 25-47.

[26] Fitzgerald, L., Johnston, R., Brignall, S., Silvestro, R., \& Voss, C. (1994). Performance measurement in service businesses. Cambridge, The Chartered Institute of Management Accountants: Black Bear Press Ltd.

[27] Bourgon, J. (2008). Performance management: it's the results that count. The Asia Pacific Journal of Public Administration, 30 (1), 4158.

[28] Goh, S. C. (1998). Towards a learning organization: the strategic building blocks. Sam Advanced Management Journal, Spring, 15-22.

[29] Morris, L. E. (1994). Development strategies for the knowledge era, in Chawla, S., \& Renesch, J. (1994). Learning organizations: developing cultures for tomorrow's workplace. Oregon, Portland: Productivity Press. 